\title{
Journal of Economics Library
}

www.kspjournals.org

\begin{tabular}{lll}
\hline Volume 4 & June 2017 & Issue 2 \\
\hline
\end{tabular}

\section{A Predictive Analysis of the Indian FMCG Sector using Time Series Decomposition - Based Approach}

\author{
By Jaydip SEN ${ }^{\text {a }}$ \& Tamal DATTA CHAUDHURI ${ }^{\mathrm{b}}$
}

\begin{abstract}
Stock price movements being random in its nature, prediction of stock prices using time series analysis presents a very difficult and challenging problem to the research community. However, over the last decade, due to rapid development and evolution of sophisticated algorithms for complex statistical analysis of large volume of time series data, and availability of high-performance hardware and parallel computing architecture, it has become possible to efficiently process and effectively analyze voluminous and highly diverse stock market time series data effectively, in real-time. Robust predictive models are being built for accurate forecasting of values of highly random variables such as stock price movements. This paper has presented a highly reliable and accurate forecasting framework for predicting the time series index values of the fast moving consumer goods (FMCG) sector in India. A time series decomposition approach is followed to understand the behavior of the FMCG sector time series for the period January 2010 till December 2016. Based on the structural analysis of the time series, six methods of forecast are designed. These methods are applied to predict the time series index values for the months of 2016 Extensive results are presented to demonstrate the effectiveness ofthe proposed decomposition approaches of time series and the efficiency of the six forecasting methods. Keywords. Time series decomposition, Trend, Seasonal, Random, Holt Winters Forecasting model, Auto Regression (AR), Moving Average (MA), Auto Regressive Integrated Moving Average (ARIMA), Partial Auto Correlation Function (PACF), Auto Correlation Function (ACF).
\end{abstract}

JEL. G11, G14, G17, C63.

\section{Introduction}

$\mathrm{O}$ ne of the most exciting challenges to the researchers working in the field of machine learning and analytics is developing an accurate and efficient forecasting framework for predicting stock prices. Researchers working in this field have proposed various technical, fundamental and statistical indicators for predicting stock prices. (Sen \& Datta Chaudhuri, 2016a; Sen \& Datta Chaudhuri, 2016b; Sen \& Datta Chaudhuri, 2016c) proposed a novel approach towards portfolio diversification and prediction of stock prices. The authors argued that different sectors in an economy do not exhibit identical pattern of variations in their stock prices. Different sectors exhibit different trend patterns, different seasonal characteristics and also differ in the randomness in their time series. While on one side the efficient market hypothesis has focused on the randomness aspect of stock price movements, on the other side, there are propositions to disprove the hypothesis delving into various fundamental characteristics of different stocks. We contend that besides the differences in the fundamental

${ }^{a \dagger}$ Praxis Business School, Bakrahat Road, Off Diamond Harbor Road, Kolkata - 700104, West Bengal, India.

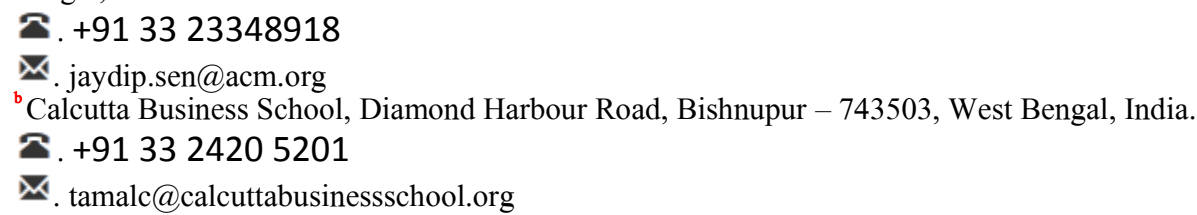




\section{Journal of Economics Library}

characteristics among stocks of different companies, performances of different stocks also have a lot to do with the sectors to which the stocks belong. Since each sector has its own set of factors influencing its behavior, the price movements of stocks belonging to different sectors are guided by these factors. The factors responsible for the phenomenal growth of the information technology (IT) sector in India are different from those which have made the metals sector in the country sluggish, or the FMCG sector grow at a slow pace. From the point of view of investors in the stock market, it is critical to identify these factors and analyze them effectively for optimal portfolio choice and also for churning of the portfolio.

In this paper, we focus on the time series pattern of the FMCG sector in India in order to understand its distinguishing characteristics. We use the monthly time series index values of the Indian FMCG sector during the period January 2010 till December 2016 as per the Bombay Stock Exchange (BSE). We decompose the time series using R programming language. We, then, illustrate how the time series decomposition approach provides us with useful insights into various characteristics and properties of the FMCG sector time series. It is further demonstrated that a careful and deeper study of the trend, seasonal and random components values of the time series enables one to understand the growth pattern, the seasonal characteristics and the degree of randomness exhibited by the time series index values. We also propose an extensive framework for time series forecasting in which we present six different approaches of prediction of time series index values. We critically analyze the six approaches and also explain the reason why some methods perform better and produce lower values of forecast error in comparison to other methods.

The rest of the paper is organized as follows. Section 2 presents the detailed methodology used in this work. It provides the details of the method of decomposition of time series into its various components. Section 3 depicts the results of decomposition of the FMCG sector time series index values into its trend, seasonal and random components. Based on the decomposition results, several characteristics and behavior exhibited by the FMCG sector time series are also analyzed. Section 4 provides comprehensive details of six forecasting methods that are proposed in this work. Section 5 presents extensive results on the performance of the six forecasting methods on the FMCG sector time series data. A comparative analysis of the techniques is also provided on the basis of six different metrics of the forecasting techniques: maximum error, minimum error, mean error, standard deviation of error, the root mean square error (RMSE), and the ratio of the RMSE value and the mean index value. Section 6 presents a brief discussion on some of the existing work in the literature on time series forecasting with particular focus on the FMCG sector. Finally, Section 7 concludes the paper.

\section{Methodology}

The methodology followed in this work is discussed in this section. The programming language $\mathrm{R}$ has been used in all phases of the work: data management, data analysis and presentation of data analysis results. (Ihaka \& Gentleman, 1996) gave a detailed description of various capabilities of $\mathrm{R}$ programming language in data management and data analysis work. $\mathrm{R}$ is an open source language with a very rich set of libraries having in-built functions that makes it one of the most effective tools in handling data analysis projects. For the current work, we have used the monthly index data from the Bombay Stock Exchange (BSE) of India for the FMCG sector for the period January 2010 till December 2016. The monthly index values of the FMCG sector for the 7 years are then stored in a plain text (.txt) file. This plain text file now contains 84 index values corresponding to the 84 months in the 7 year period under our study. The text file is then read into an $\mathrm{R}$ data object using the $\operatorname{scan}$ () function. The $\mathrm{R}$ data object is then converted into a time series object by applying the $t s()$ function with a frequency value of 12 . The frequency value is chosen to be 12 so that the seasonality characteristics of the time series for each month can be analysed. The 


\section{Journal of Economics Library}

time series data object in $\mathrm{R}$ is then decomposed into its three components - trend, seasonal and random - using the decompose() function which is defined in the TTR library in R environment. We plot the graphs of the FMCG time series data as well as its three components so that further analysis can be made on the behavior of the time series and its three components.

After carrying out a comprehensive analysis of the decomposition results of the time series of the FMCG sector, we propose six different approaches of forecasting of time series index values. In order to compute the forecast accuracy of each method, we build the forecast models using the FMCG time series data for the period January 2010 till December 2015, and apply the models to forecast time series index values for each month of the year 2016. Since the actual values of the time series for all months of 2016 are already available with us, we compute the error in forecasting using each method of forecast that we have proposed. Comparative analysis of the methods of forecasting is done based on several useful metrics and reasons for which a particular method performs better than the other methods for the FMCG sector time series are clearly analyzed. A detailed comparative analysis, highlighting which method performs best under what situations and for what type of time series, is also presented.

Demonstrated how effectively time series decomposition approach can be utilized in robust analysis and forecasting of the Indian Auto sector. In another different work, (Sen \& Datta Chaudhuri, 2016a; Sen \& Datta Chaudhuri 2016b) analyzed the behavior of two different sectors of Indian economy - the small cap sector and the capital goods sector - the former having a dominant random component while the latter exhibiting a significant seasonal component. Following another approach of time series analysis, (Sen \& Datta Chaudhuri, 2016d) studied the behavior of the Indian information technology (IT) sector time series and the Indian capital goods sector time series. In yet another work, using the time series decomposition-based approach, (Sen \& Datta Chaudhuri, 2016e) illustrated how time series analysis enables us to check the consistency between the fund style and actual fund composition of a mutual fund.

In this work, we demonstrate how time series decomposition-based approach enables one in analysing and understanding the behavior and different properties of the FMCG time series of the Indian economy based on time series data for the period January 2010 till December 2016. We also investigate which forecasting approach is most effective for the FMCG time series. For this purpose, we compare several approaches of forecasting and identify the one that produces the minimum value of forecasting error. We critically analyze all the proposed forecasting approaches, and explain why a particular approach has worked most effectively while some others have not done so for the FMCG time series data.

\section{Time Series Decomposition Results}

We present the decomposition results for the time series of the FMCG sector index values as per the records of the BSE for the period January 2010 till December 2016. First, we create a plain text (.txt) file containing the monthly index values of the FMCG sector for the period January 2010 till December 2016. This file contained 84 records corresponding to the 84 months in the 7 years under study. We used the $\operatorname{scan}$ () function in R language to read the text file and stored it in an $\mathrm{R}$ data object. Then, we converted this $\mathrm{R}$ data object into a time series object using the $\mathrm{R}$ function $t s$ (). We used the value of the frequency parameter in the $t_{s}$ () function as 12 so that the decomposition of the time series is carried out on monthly basis. After creating the time series data object, we used the function plot( ) in R to draw the plot of the FMCG sector time series during the period January 2010 till December 2016. Figure 1 depicts the graph of the FMCG sector time series. 


\section{Journal of Economics Library}

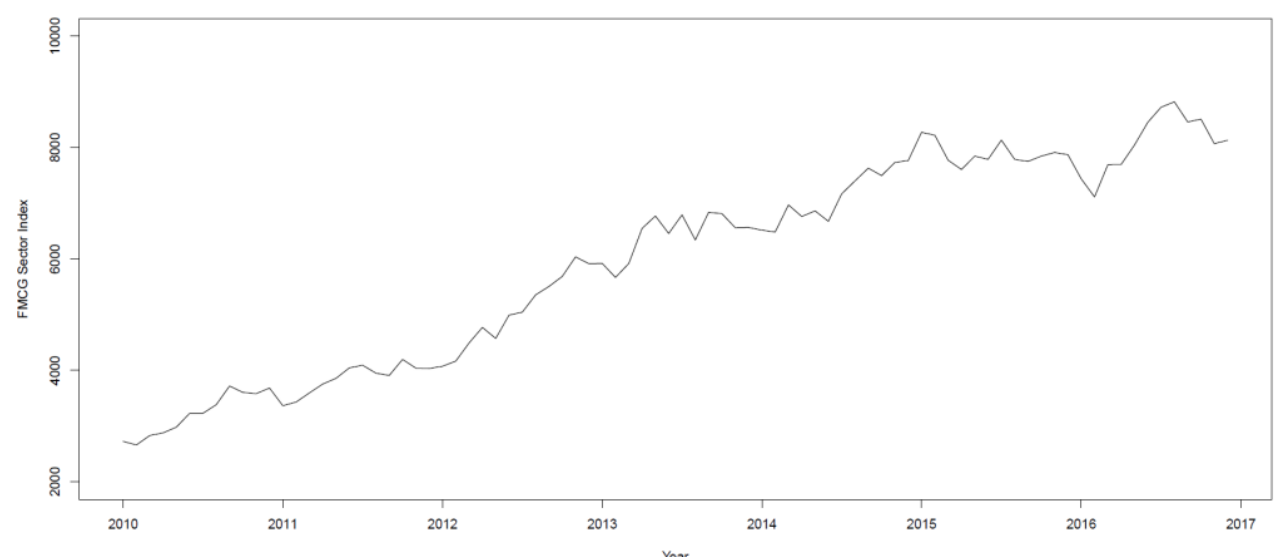

Figure1. Time series of FMCG Sector Index in India (Period: Jan 2010 - Dec 2016)

To obtain further insights into the characteristics of the time series, we decomposed the time series object into its three components - trend, seasonal and random. The decomposition of the time series object is done using the decompose( ) function defined in the TTR library in R programming environment. The decompose() function is executed with the FMCG time series object as its parameter and the three components of the time series are obtained. Figure 2 presents the graphs of FMCG sector time series and its three components. Figure 2 consisted of four boxes arranged in a stack. The boxes display the overall time series, the trend, the seasonal and the random component respectively arranged from top to bottom in that order.

From Figure 1, it may be seen that the time series of the FMCG sector consistently increased during the period January 2010 till December 2014. During the year 2015, the time series was rather flat in nature. However, during the period January 2016 till August 2016, the FMCG sector time series exhibited a positive slope before it started experiencing a fall that continued till the end of the year 2016. Figure 2 shows the decomposition results of the FMCG time series. The three components of the time series are shown separately so that their relative behavior can be visualized.

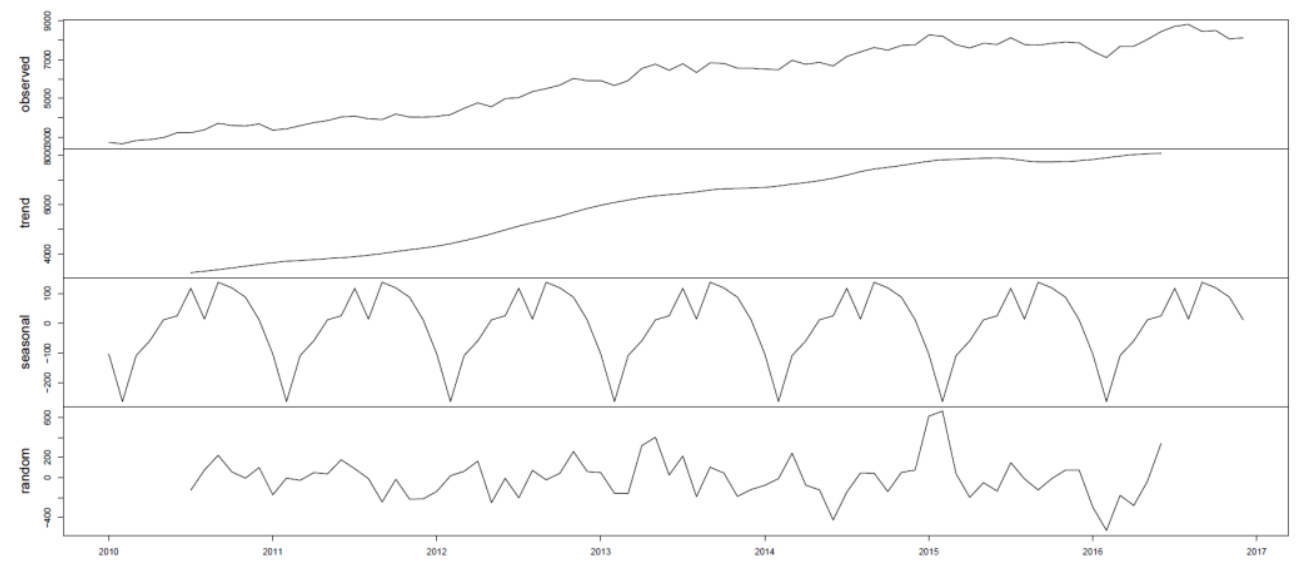

Figure 2. Decomposition results of the FMCG sector index time series into its three components(Period: Jan 2010 - Dec 2016)

Table 1 presents the numerical values of the time series data and its three components. The trend and the random components are not available for the period January 2010 - June 2010 and also for the period July 2016 - December 2016. This is due to the fact that trend computation needs long term data. Coughlan (2015) illustrated that the decompose() function in $\mathrm{R}$ uses a 12-month moving average 


\section{Journal of Economics Library}

method to compute the trend values in a time series. Hence, in order to compute trend values for the period January2010 - June 2010, the decompose() function needs time series data for the period July 2009 - December 2009. Since, the data for the period July 2009 - December 2009 are not available in the dataset under our study, the trend values for the period January 2010 - June 2010 could not be computed. For similar reason, the trend values for the period July 2016 - December 2016 , could not be computed due to non- availability of the time series record for the period January 2017 - June 2017 in our dataset. It may be noted from Table 1 that the seasonal value for a given month remains constant throughout the entire period of study. For example, the seasonal component has a constant value of 22 for the month of January in every year from 2010 till 2016. It is interesting to note that due to the non-availability of the trend values for the periods January 2010 June 2010 and July 2016 - December 2016, the random components for these periods could not also be computed by the decompose() function. In other words, since the aggregate time series values are given by the sum of the corresponding trend, seasonal and random component values, and because of the fact that the seasonal value for a given month remains the same throughout, non-availability of trend values for a period makes the random components values also unavailable for the same period.

Table 1. Time series index values of the Indian FMCG Sector and its components (Period: Jan 2010-Dec 2016)

\begin{tabular}{|c|c|c|c|c|c|}
\hline Year & Month & Aggregate Index & Trend & Seasonal & Random \\
\hline \multirow{12}{*}{2010} & January & 2725 & & -103 & \\
\hline & February & 2662 & & -263 & \\
\hline & March & 2831 & & -108 & \\
\hline & April & 2878 & & -58 & \\
\hline & May & 2981 & & 12 & \\
\hline & June & 3230 & & 26 & \\
\hline & July & 3230 & 3236 & 119 & -125 \\
\hline & August & 3385 & 3295 & 15 & 75 \\
\hline & September & 3720 & 3359 & 139 & 222 \\
\hline & October & 3605 & 3427 & 120 & 57 \\
\hline & November & 3583 & 3500 & 89 & -6 \\
\hline & December & 3684 & 3571 & 13 & 101 \\
\hline \multirow{12}{*}{2011} & January & 3366 & 3641 & -103 & -172 \\
\hline & February & 3432 & 3700 & -263 & -5 \\
\hline & March & 3596 & 3732 & -108 & -28 \\
\hline & April & 3755 & 3764 & -58 & 49 \\
\hline & May & 3858 & 3808 & 12 & 37 \\
\hline & June & 4045 & 3842 & 26 & 177 \\
\hline & July & 4093 & 3886 & 119 & 88 \\
\hline & August & 3950 & 3946 & 15 & -11 \\
\hline & September & 3910 & 4014 & 139 & -243 \\
\hline & October & 4197 & 4094 & 120 & -17 \\
\hline & November & 4041 & 4166 & 89 & -214 \\
\hline & December & 4035 & 4235 & 13 & -213 \\
\hline \multirow{12}{*}{2012} & January & 4074 & 4315 & -103 & -137 \\
\hline & February & 4167 & 4413 & -263 & 17 \\
\hline & March & 4493 & 4538 & -108 & 63 \\
\hline & April & 4772 & 4667 & -58 & 164 \\
\hline & May & 4574 & 4812 & 12 & -250 \\
\hline & June & 4992 & 4973 & 26 & -7 \\
\hline & July & 5046 & 5129 & 119 & -202 \\
\hline & August & 5356 & 5268 & 15 & 73 \\
\hline & September & 5507 & 5390 & 139 & -23 \\
\hline & October & 5687 & 5524 & 120 & 43 \\
\hline & November & 6038 & 5689 & 89 & 260 \\
\hline & December & 5916 & 5842 & 13 & 61 \\
\hline \multirow{11}{*}{2013} & January & 5922 & 5976 & -103 & 49 \\
\hline & February & 5669 & 6090 & -263 & -158 \\
\hline & March & 5919 & 6186 & -108 & -159 \\
\hline & April & 6549 & 6289 & -58 & 319 \\
\hline & May & 6772 & 6358 & 12 & 402 \\
\hline & June & 6458 & 6407 & 26 & 26 \\
\hline & July & 6792 & 6458 & 119 & 215 \\
\hline & August & 6342 & 6517 & 15 & -190 \\
\hline & September & 6838 & 6595 & 139 & 104 \\
\hline & October & 6814 & 6648 & 120 & 46 \\
\hline & November & 6562 & 6661 & 89 & -187 \\
\hline
\end{tabular}

JEL, 4(2), J. Sen, \& T.D. Chaudhuri, p.206-226. 
Journal of Economics Library

\begin{tabular}{|c|c|c|c|c|c|}
\hline & December & 6567 & 6673 & 13 & -119 \\
\hline \multirow{12}{*}{2014} & January & 6518 & 6698 & -103 & -77 \\
\hline & February & 6484 & 6758 & -263 & -11 \\
\hline & March & 6971 & 6835 & -108 & 244 \\
\hline & April & 6763 & 6897 & -58 & -75 \\
\hline & May & 6864 & 6974 & 12 & -123 \\
\hline & June & 6676 & 7073 & 26 & -423 \\
\hline & July & 7170 & 7196 & 119 & -145 \\
\hline & August & 7402 & 7342 & 15 & 45 \\
\hline & September & 7631 & 7448 & 139 & 44 \\
\hline & October & 7497 & 7516 & 120 & -140 \\
\hline & November & 7734 & 7592 & 89 & 53 \\
\hline & December & 7767 & 7680 & 13 & 75 \\
\hline \multirow{12}{*}{2015} & January & 8275 & 7766 & -103 & 612 \\
\hline & February & 8222 & 7823 & -263 & 663 \\
\hline & March & 7773 & 7844 & -108 & 37 \\
\hline & April & 7607 & 7863 & -58 & -198 \\
\hline & May & 7847 & 7885 & 12 & -51 \\
\hline & June & 7789 & 7897 & 26 & -134 \\
\hline & July & 8134 & 7867 & 119 & 149 \\
\hline & August & 7788 & 7786 & 15 & -12 \\
\hline & September & 7752 & 7736 & 139 & -123 \\
\hline & October & 7847 & 7736 & 120 & -10 \\
\hline & November & 7912 & 7748 & 89 & 75 \\
\hline & December & 7872 & 7784 & 13 & 75 \\
\hline \multirow{12}{*}{2016} & January & 7439 & 7837 & -103 & -295 \\
\hline & February & 7114 & 7904 & -263 & -527 \\
\hline & March & 7692 & 7977 & -108 & -177 \\
\hline & April & 7697 & 8034 & -58 & -279 \\
\hline & May & 8045 & 8069 & 12 & -36 \\
\hline & June & 8453 & 8086 & 26 & 341 \\
\hline & July & 8725 & & 119 & \\
\hline & August & 8822 & & 15 & \\
\hline & September & 8461 & & 139 & \\
\hline & October & 8511 & & 120 & \\
\hline & November & 8071 & & 89 & \\
\hline & December & 8131 & & 13 & \\
\hline
\end{tabular}

From Table 1, some important observations are made. First, we can see that seasonal component has the maximum value of 139 in the month of September, while the lowest value of seasonality -263 is observed in the month of February. The seasonal component is found to have high positive values during the months of July, September and October, while negative values of seasonality are observed during the months of January till April. In order to analyze the impact of seasonality on the FMCG time series, we computed some statistics on the seasonal component values. We computed the percentage contribution of the seasonal component on the aggregate time series values and found the following. The maximum, the minimum, the mean of the absolute values, and the standard deviation of the percentage of the seasonal components with respect to the aggregate time series values were found to be 3.74, -9.88, 1.72 and 2.42 respectively. The maximum percentage of seasonal component was found in the month of September 2010, while the minimum was observed in the month of February 2010. While the low value of the mean percentage indicated that the time series was not seasonal, the high value of standard deviation in comparison to the mean value implied that the seasonal percentages exhibited high level of dispersion among themselves.

Second, the trend component of the time series consistently increased during the period July 2010 till December 2014. However, the trend started became sluggish and flattened out from January 2015 and continued to maintain the same pattern till July 2016. The maximum, the minimum, the mean, and the standard deviation of the percentage of the trend component with respect to the aggregate time series were found to be $111.10,90.30,100.16$ and 3.94 respectively indicating that the trend was the single most dominant component in the time series. The maximum percentage of trend component was found in the month of February 2016, while the minimum was found in the month of February 2010.

Third, the maximum and the minimum values of the random component of the time series were found to be 663 and -527 respectively. These values are quite

JEL, 4(2), J. Sen, \& T.D. Chaudhuri, p.206-226. 


\section{Journal of Economics Library}

modest in comparison to the aggregate time series values. In order to understand the contribution of the random component on the overall time series, we computed the maximum, the minimum, the mean of the absolute values and the standard deviation of the percentage of random component values with respect to the aggregate time series values. These values were found to be $8.06,-7.41,2.42$ and 3.19 respectively. It indicated that while the random component is not dominant in the time series, the values of the random component exhibited large deviations across their mean value. The random component contributed its maximum percentage to the aggregate timeseries in the month of December 2014, while the lowest percentage was found in the month of February 2016.

The overall conclusion is that the FMCG time series is primarily dominated by its trend component, while seasonal and random components are having not significant contributions to the aggregate time series. However, the seasonal and random components exhibited significant variations across their mean values.

\section{Proposed Forecasting Methods}

In this Section, we present a set of interesting forecasting methods that we have applied on the time series data of the FMCG sector index. We propose six different approaches to forecasting and present the performance of these approaches on the FMCG sector time series data. For the purpose of comparative analysis of different approaches of forecasting, we use five different metrics and identify which method leads to the lowest value of forecasting error. We also critically analyze the approaches and argue why one method performs better than the others on the given dataset of FMCG sector time series index for the period January 2010 - December 2016. In the following, we first describe the six approaches, and then provide the detailed results as these forecasting methods are applied on the FMCG sector dataset.

Method 1: In this method, we use the FMCG sector time series data for the period January 2010 till December 2015 for the purpose of forecasting the monthly index values for each month of the year 2016. The HoltWinters() function in $\mathrm{R}$ library forecasthas been used for this purpose. In order to build a robust forecasting framework, the HoltWinters model is used with a changing trend and an additive seasonal component that best fits the FMCG time series index data. The forecast horizon in the HoltWinters model is chosen to be 12 so that the forecasted values for all months of 2016 can be obtained by using the method at the end of the year 2015. Forecast error is computed for each month of 2016 and an overall RMSE value is also derived for this method.

Method II: In this approach, the FMCG sector index value for each month of the year 2016 is forecasted using the HoltWinters () method with a forecast horizon of 1 month. For example, for the purpose of forecasting the index for the month of March 2016, the index values of the FMCG sector from January 2010 till February 2016 are used to develop the forecasting model. As in Method I, the HoltWinters model is used with a changing trend and an additive seasonal component. Since the forecast horizon is short, the model is likely to produce higher accuracy in forecasting compared to the approach followed in Method I that used a forecast horizon of 12 months. The forecast error corresponding to each month of 2016 and an overall RMSE value for the model is computed.

Method III: In this forecasting approach, we first use the time series data for the FMCG sector index for the period January 2010 till December 2015 and derive the trend and the seasonal component values. This method yields the values of the trend component of the time series for the period from July 2010 till June 2015. Using the series of trend values for the period July 2010 till June 2015, forecast for the trend values for the period July 2015 till June 2016 are made using the HoltWinters () function in $\mathrm{R}$ with a changing trend component level but without any seasonality component. In other words, for forecasting the trend values, in the HoltWinters( ) function in R, we set the parameter 'beta' = TRUE and the parameter 'gamma' = FALSE, in the HoltWinters() function in R. The forecasted 


\section{Journal of Economics Library}

trend values are added to the seasonal component values of the corresponding months (based on the time series data for the period January 2010 till December 2015) to arrive at the forecasted aggregate of the trend and seasonal components. Now, we consider the time series of the FMCG sector index values for the entire period, i.e., from January 2010 till December 2016, and decompose it into its trend, seasonal and random components. Based on thistime series, we compute the aggregate of the actual trend and the actual seasonal component values for the period July 2015 till June 2016. We derive the forecasting accuracy of this method by calculating the percentage of deviation of the aggregate of the actual trend and the actual seasonal component values with respect to the corresponding aggregate values of the forecasted trend and past seasonal components for each month during July 2015 to June 2016. An overall RMSE value for this method is also computed.

Method IV: The approach followed in this method is exactly similar to that used in Method III. However, unlike Method III that used HoltWinters() function with changing trend component and a zero seasonal component, this method uses a linear regression model for the purpose of forecasting the trend component values for the period from July 2015 till June 2016. The $\mathrm{Im}$ () function in R is used for building a bivariate linear regression model with trend component as the response variable and time as the predictor variable. The regression model is built using the trend values for the period July 2010 till June 2015. The aggregate of the predicted trend values and the past seasonal values are compared with the aggregate of the actual trend values and the actual seasonal values for the period from July 2015 till June 106. The error in forecasting and an overall RMSE value is computed as in Method III.

Method V: We use Auto Regressive Integrated Moving Average (ARIMA) based approach of forecasting in this method. For building the ARIMA model, we use the FMCG sector time series data for the period January 2010 till December 2015. Using this training data set and executing the auto.arima() function defined in the forecast package in $\mathrm{R}$, we compute values of the three parameters of the Auto Regressive Moving Average (ARMA) model, i.e. the autoregression parameter $(p)$, the difference parameter $(d)$, and the moving average parameter $(q)$. Next, we build the ARIMA model of forecasting using the arima() function in $\mathrm{R}$ with the two parameters: (i) the FMCG time series R object (based on data for the period from January 2010 till December 2015), (ii) the order of the ARMA i.e., the values of the three parameters $(p, d, q)$.Using the resultant ARIMA model, we call the function forecast.Arima( ) with parameters: (i) ARIMA model object, and (ii) forecast horizon $=12$ months (in this approach). Since a forecast horizon of 12 months is used, we compute the forecasted values of each month of the year 2016 at the end of the year 2015. The error in forecasting and the RMSE value are also computed.

Method VI: Similar to Method V, this forecasting method is also based on an ARIMA model. However, unlike Method V that used forecast horizon of 12 months, this method uses a short forecast horizon of 1 month. For the purpose of forecasting, the ARIMA model is built using time series data for the period January 2010 till the month previous to the month for which forecasting is being made. For example, for the purpose of prediction of the time series index for the month of May 2016, the time series data from January 2010 till April 2016 is used for building the ARIMA model. Since the training data set for building the ARIMA model constantly changes in this approach, we evaluate the ARIMA parameters (i.e., $p, d$, and $q$ ) before every round of forecasting. In other words, for each month of the year 2016, before we make the forecast for the next month, we compute the values of the three parameters of the ARIMA model.

JEL, 4(2), J. Sen, \& T.D. Chaudhuri, p.206-226. 


\section{Journal of Economics Library}

\section{Forecasting Results}

In this Section, we provide results on the performance of the six forecasting methods.

Method I: The results obtained using these methods are presented in Table 2. In Figure 3, we have plotted the actual values of the FMCG sector index and the corresponding predicted values for each month of the year 2016.

Table 2. Computation Results using Method I

\begin{tabular}{ccccc}
\hline Month & Actual Index & Forecasted Index & \% Error & RMSE \\
\hline (A) & $(\mathrm{B})$ & $(\mathrm{C})$ & $(\mathrm{C}-\mathrm{B}) / \mathrm{B} * 100$ & \\
Jan & 7439 & 7928 & 6.57 & \\
Feb & 7114 & 7727 & 8.62 & \\
Mar & 7692 & 7767 & 0.98 & \\
Apr & 7697 & 7915 & 2.83 & \\
May & 8045 & 8126 & 1.01 & \multirow{2}{*}{. } \\
Jun & 8453 & 8110 & 4.06 & \\
Jul & 8725 & 8415 & 3.55 & \\
Aug & 8822 & 8259 & 6.38 & \\
Sep & 8461 & 8469 & 0.09 & \\
Oct & 8511 & 8550 & 0.46 & \\
Nov & 8071 & 8601 & 6.57 & \\
Dec & 8131 & 8556 & 5.23 & \\
\hline
\end{tabular}

Observations on Method I: We observe from Table 2 that the forecasted values very closely match the actual values of the FMCG sector index for all months in the year 2016. The highest value of the error percentage (8.62) has been found to be quite low which corresponds to the month of February 2016. The forecast for the month of September 2016 exhibited the lowest percentage of error (0.09), which is almost negligible. The reason for such accuracy for this method of forecasting is due to the modest growth of the FMCG sector during the year 2016. Since there was no sharp rise or fall of the actual index value in any month of 2016, the HoltWinters method of forecasting with a long forecast horizon of 12 months that effectively forecasted a smoothened average value turned out to be a very effective method. The RMSE value for this method is found out to be 373 that is only 4.61 percent of the mean value of 8097 of the actual index of the FMCG sector index during 2016. This indicates that Method I is very accurate in forecasting the FMCG sector time series index.

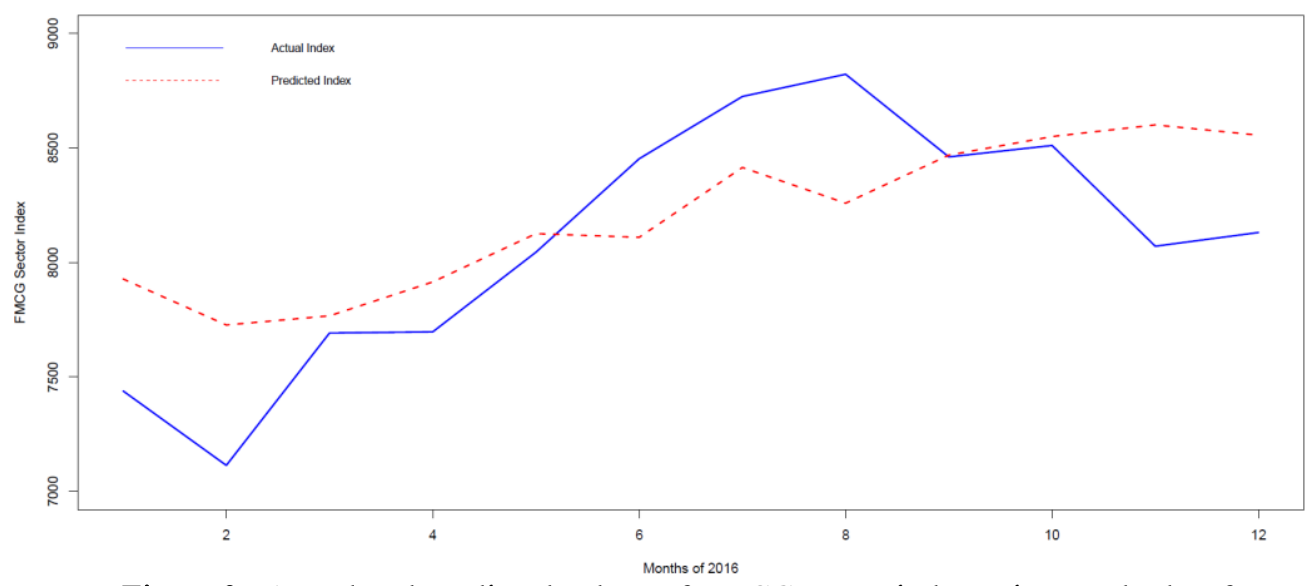

Figure 3. Actual and predicted values of FMCG sector index using Method I of forecasting. (Period: Jan 2016 - Dec 2016).

Method II: The results of forecasting using Method II are presented in Table 3. In Figure 4, the actual index values and their corresponding predicted values are plotted. 


\section{Journal of Economics Library}

Table 3. Computation Results using Method II

\begin{tabular}{ccccc}
\hline Month & Actual Index & Forecasted Index & \% Error & RMSE \\
\hline (A) & $(\mathrm{B})$ & $(\mathrm{C})$ & $(\mathrm{C}-\mathrm{B}) / \mathrm{B} * 100$ & \\
Jan & 7439 & 7928 & 6.57 & \\
Feb & 7114 & 7395 & 3.95 & \\
Mar & 7692 & 7248 & 5.77 & \\
Apr & 7697 & 7723 & 0.34 & \\
May & 8045 & 7883 & 2.01 & \multirow{2}{*}{ Ju3 } \\
Jun & 8453 & 8024 & 5.08 & \\
Jul & 8725 & 8555 & 1.95 & \\
Aug & 8822 & 8558 & 2.99 & \\
Sep & 8461 & 9000 & 6.37 & \\
Oct & 8511 & 8682 & 2.01 & \\
Nov & 8071 & 8588 & 6.41 & \\
Dec & 8131 & 8165 & 0.42 & \\
\hline
\end{tabular}

Observations on Method II: We observe from Table 3 and Figure 4 that the forecasted values very closely match with the actual values of the time series index. The lowest value of error percentage is found to be 0.34 which occurred in the month of April 2016, while the highest error percentage value of 6.57 was found in the month of January 2016. The RMSE value for this method is 343, which even lower than that obtained in Method I earlier. The RMSE value contributes only 4.24 percent of the mean value of the actual index of the FMCG sector for the year 2016. This clearly demonstrates that HoltWinters additive model with a prediction horizon of 1 month can very effectively and accurately forecast FMCG sector index values.

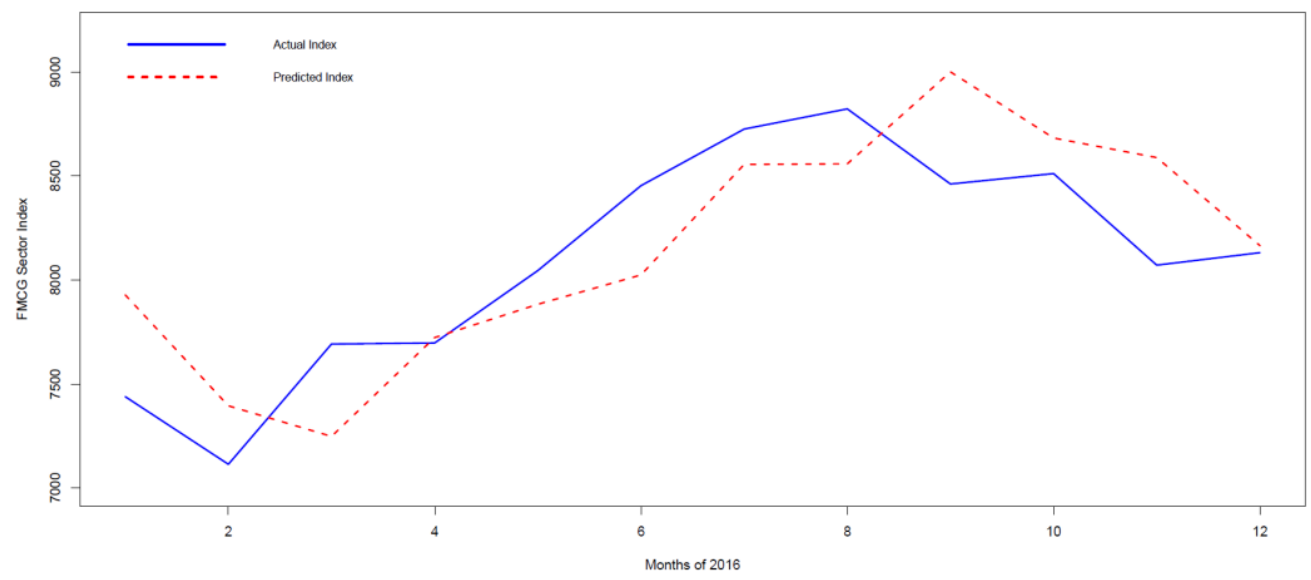

Figure 4. Actual and predicted values of FMCG sector index using Method II of forecasting.(Period: Jan 2016 - Dec 2016).

Table 4. Computation Results using Method III

\begin{tabular}{|c|c|c|c|c|c|c|c|c|}
\hline Month & $\begin{array}{l}\text { Actual } \\
\text { Trend }\end{array}$ & $\begin{array}{c}\text { Actual } \\
\text { Seasonal }\end{array}$ & $\begin{array}{c}\text { Actual } \\
\text { (Trend + } \\
\text { Seasonal) }\end{array}$ & $\begin{array}{c}\text { Forecasted } \\
\text { Trend }\end{array}$ & $\begin{array}{c}\text { Past } \\
\text { Seasonal }\end{array}$ & $\begin{array}{c}\text { Forecasted } \\
\text { (Trend + } \\
\text { Seasonal) }\end{array}$ & $\%$ Error & RMSE \\
\hline $\mathrm{A}$ & B & $\mathrm{C}$ & $\mathrm{D}$ & $\mathrm{E}$ & $\mathrm{F}$ & $\mathrm{G}$ & $(G-D) / D * 100$ & \\
\hline Jul & 7867 & 119 & 7986 & 7909 & 75 & 7984 & 0.02 & \\
\hline Aug & 7786 & 15 & 7801 & 7921 & 4 & 7925 & 1.59 & \\
\hline Sep & 7736 & 139 & 7875 & 7933 & 150 & 8083 & 2.64 & \\
\hline Oct & 7736 & 120 & 7856 & 7945 & 109 & 8054 & 2.52 & \\
\hline Nov & 7748 & 89 & 7837 & 7957 & 60 & 8017 & 2.30 & \\
\hline Dec & 7784 & 13 & 7797 & 7969 & -16 & 7953 & 2.00 & 132 \\
\hline Jan & 7837 & 103 & 7940 & 7981 & -58 & 7923 & 0.21 & \\
\hline Feb & 7904 & -263 & 7641 & 7993 & -172 & 7821 & 2.36 & \\
\hline Mar & 7977 & -108 & 7869 & 8005 & -86 & 7919 & 0.64 & \\
\hline Apr & 8034 & -58 & 7976 & 8017 & -16 & 8001 & 0.31 & \\
\hline May & 8069 & 12 & 8081 & 8029 & 6 & 8035 & 0.57 & \\
\hline Jun & 8086 & 26 & 8112 & 8041 & -56 & 7985 & 1.57 & \\
\hline
\end{tabular}

Method III: The results of forecasting using this method are presented in Table 4. Figure 5 depicts the actual index values and their corresponding predicted values 


\section{Journal of Economics Library}

for all months of the year 2016 using Method III of forecasting. The actual trend and seasonal component values for the period from July 2015 till June 2016 (computed based on the time series data for the period from January 2010 till December 2016) and their aggregated monthly values are noted in Columns $B, C$ and $D$ respectively in Table 4 . The forecasted trend values (using HoltWinters method with changing trend component and nil seasonal component and with a forecast horizon of 12 months) and the past seasonal component values (based on time series data for the period from January 2010 till December 2015) and their corresponding aggregate values are noted in columns $E, F$ and $G$ respectively in Table 4. The error value for each month and an overall RMSE value for this method are also computed.

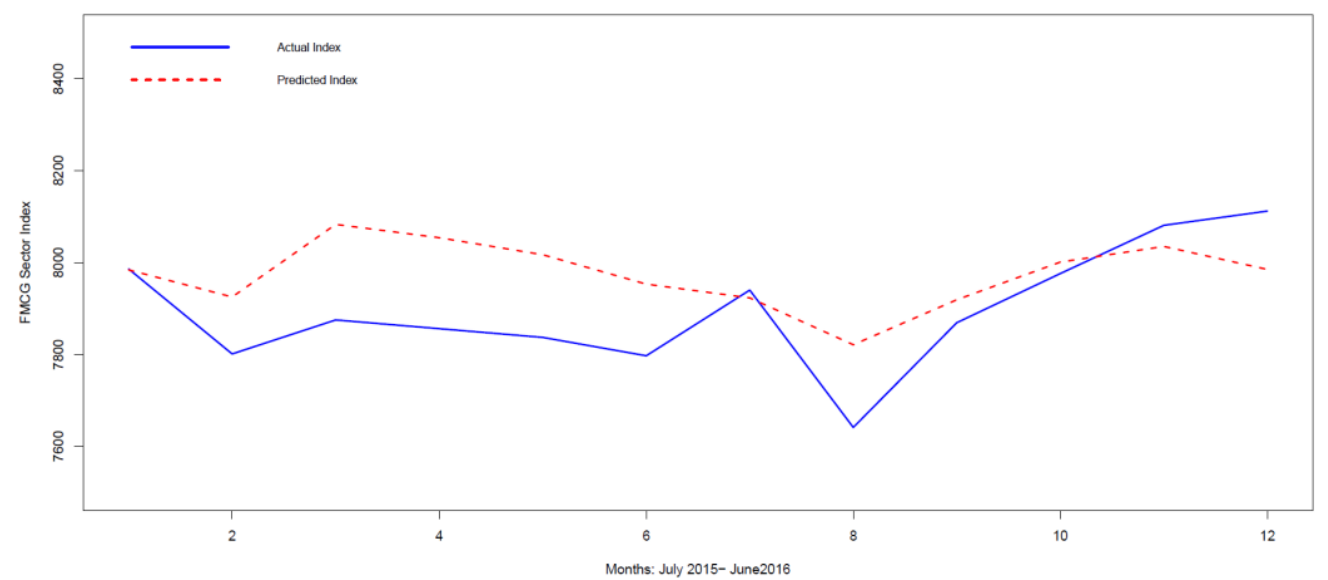

Figure 5. Actual and predicted values of the sum of trend and seasonal components of FMCG sector index using Method III of forecasting (Period: Jan 2016 - Dec 2016)

Observations on Method III: It may be observed from Table 4 and Figure 5 that the error in forecasting has been quite small for all months during the period July 2015 till June 2016. The lowest value of the error percentage had been 0.02 that occurred in the month of July 2015, while the highest value of error percentage of 2.64 was observed in the month of September 2015. The computed RMSE value of 132 for this method represents only 1.67 percent of the mean value of the sum of the actual trend and the actual seasonal components during the period July 2015 till June 2016. The low value of RMSE indicates that this method is very effective in forecasting the FMCG index time series index values. It is evident from Table 4 that the actual trend values of the FMCG sector increased very sluggishly over the period July 2015 till June 2016. Since the actual seasonal values are quite small compared to the trend values, the sum of the actual trend and the actual seasonal values also exhibited the same pattern of change as the trend, increasing at a very slow rate starting with a value of 7986 in July 2015 attaining a value of 8112 in June 2016. As the trend values are forecasted using HoltWinters method with a forecast horizon of 12 months, the forecasted trend values are smoothened out over the period, resulting in a series of forecasted trend values exhibiting a very slow rate of increase. In fact, the forecasted trend started with a value of 7909 in the month of July 2015, attained a value of 8041 in June 2016. Since the past seasonal values (i.e., the seasonal values based on the FMCG sector time series for the period January 2010 till December 2015), were also very low compared to the corresponding trend values, the sum of the forecasted trend values and their respective past seasonal values increased very sluggishly exhibiting the same pattern as the forecasted trend values. The slow rate of increase for both the actual series and the forecasted series made the two series match closely with each other, thereby making this method of forecast extremely accurate for the FMCG sector index time series. 


\section{Journal of Economics Library}

Method IV: Table 5 presents the results of forecasting for Method IV. Figure 6 shows the actual index values and their corresponding predicted values using Method IV of forecasting for all months during the period July 2015 till June 2016. The values of the actual trend component and the actual seasonal component for the period July 2015 till June 2016 (computed based on the time series data for the period January 2010 till December 2016) and their aggregated monthly values are listed in Columns $B, C$ and $D$ respectively in Table 4. In Method III, the trend values are forecasted using HoltWinters() function with a forecast horizon of 12 months. However, in Method IV, the forecasting of the trend values are done using a linear regression approach with the FMCG index values as the response variable and the month as the predictor variable. The forecasted trend values and the past seasonal component values (based on time series data for the period from January 2010 till December 2015) and their corresponding aggregate values listed noted in columns $E, F$ and $G$ respectively in Table 5. The percentage of error in forecasting for each month during the period July 2015 till June 2016, and an overall RMSE value are also listed.

Table 5. Computation Results using Method IV

\begin{tabular}{cccccccc}
\hline Month & $\begin{array}{c}\text { Actual } \\
\text { Trend }\end{array}$ & $\begin{array}{c}\text { Actual } \\
\text { Seasonal }\end{array}$ & $\begin{array}{c}\text { Actual } \\
\text { (Trend }+ \\
\text { Seasonal) }\end{array}$ & $\begin{array}{c}\text { Forecasted } \\
\text { Trend }\end{array}$ & $\begin{array}{c}\text { Past } \\
\text { Seasonal }\end{array}$ & $\begin{array}{c}\text { Forecasted } \\
\text { (Trend }+ \\
\text { Seasonal) }\end{array}$ & \% Error \\
\hline A & B & $\mathrm{C}$ & $\mathrm{D}$ & $\mathrm{E}$ & $\mathrm{F}$ & $\mathrm{G}$ & RMSE \\
Jul & 7867 & 119 & 7986 & 8299 & 75 & 8374 & 4.86 \\
Aug & 7786 & 15 & 7801 & 8386 & 4 & 8390 & 7.55 \\
Sep & 7736 & 139 & 7875 & 8474 & 150 & 8624 & 9.51 \\
Oct & 7736 & 120 & 7856 & 8562 & 109 & 8671 & 10.37 \\
Nov & 7748 & 89 & 7837 & 8649 & 60 & 8709 & 11.13 \\
Dec & 7784 & 13 & 7797 & 8737 & -16 & 8721 & 11.85 \\
Jan & 7837 & -103 & 7734 & 8824 & -58 & 8766 & 13.34 \\
Feb & 7904 & -263 & 7641 & 8912 & -172 & 8740 & 14.38 \\
Mar & 7977 & -108 & 7869 & 8999 & -86 & 8913 & 13.27 \\
Apr & 8034 & -58 & 7976 & 9087 & -16 & 9071 & 13.73 \\
May & 8069 & 12 & 8081 & 9174 & 6 & 9180 & 13.60 \\
Jun & 8086 & 26 & 8112 & 9262 & -56 & 9206 & 13.49 \\
\hline
\end{tabular}

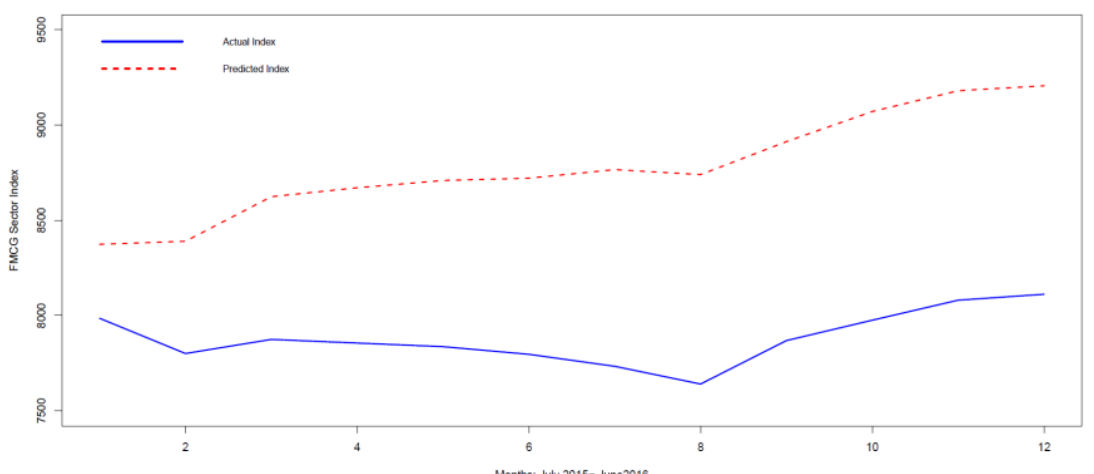

Figure 6. Actual and predicted values of the sum of trend and seasonal components of FMCG sector index using Method IV of forecasting (Period: Jan 2016 - Dec 2016)

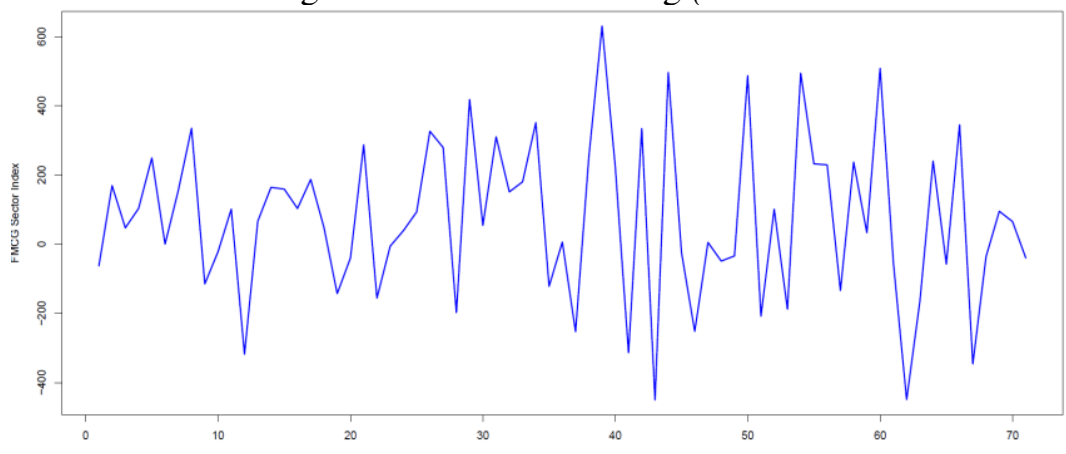

Figure 7. First-order difference of the FMCG sector time series (Period: Jan 2016 - Dec 2016)

JEL, 4(2), J. Sen, \& T.D. Chaudhuri, p.206-226. 


\section{Journal of Economics Library}

Observation on Method IV: It is clear from Table 5 and Figure 6 that unlike Method III, Method IV has produced high values of error. The lowest percentage of error (4.86) was found in the month of July 2015, while the highest error percentage value (13.73) was observed in the month of April 2016. It may also be noted from Figure 5 that the error increased consistently with time. The RMSE value for this method has been found to be 927 while the mean value of the actual sum of trend and seasonal components during the period July 2015 till June 2016 is 7897. Hence, the RMSE value is 11.74 percent of the mean value of the index, indicating that the method of forecasting is effective although it involves higher error than the methods discussed earlier. It is not difficult to understand the reason for the higher values of error produced by this method. This method used linear regression method for predicting the trend values for the period July 2015 till June 2016. Based on the previous trend values for the period July 2010 till June 2015, the linear regression computed the regression coefficients and used the values of the coefficients to compute the trend values for the period July 2015 till June 2106. Since, the trend for the period July 2010 till June 2015 had a positive slope, the regression coefficients were positive. The positive regression coefficients produced forecasted values of trend which consistently increased from a value of 8299 in July 2015 to 9262 in June 2016. Since seasonal component values were small compared to trend values, the sum of the forecasted trend and past seasonal values also exhibited the same pattern as the forecasted trend values - the sum of the forecasted trend values and the past seasonal values increased consistently from 8374 in July 2015 to 9206 in June 2016. However, the actual trend values during the target period of July 2015 till June 2016 were very sluggish. The actual trend increased very slowly from a value of 7867 in July 2015 to 8086 in July 2016. Since the forecasted trend values increased a much faster rate than the actual rate of increase of the trend time series, the method yielded increasingly higher values of error with time.

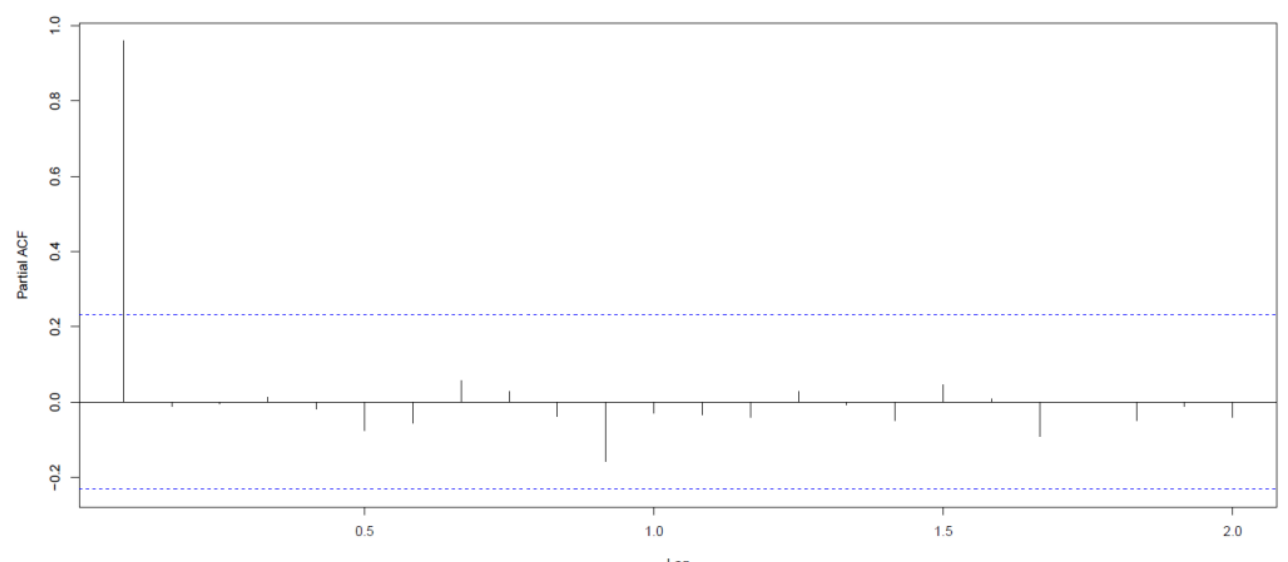

Figure 8. Plot of the partial auto correlation function (PACF) of the FMCG sector time series with max lag of 2 years (Period: Jan 2016 - Dec 2016)

Method V: This method of forecasting is based on ARIMA technique with a forecast horizon of 12 months. Applying auto.arima() function defined in the library forecast in R, on the FMCG sector time series index values for the period January 2010 till December 2015, we obtain the parameter values for the time series as: $p=0, d=1$, and $q=1$. We cross verify the values of $p, d$, and $q$ by plotting the partial auto correlation function (PACF), the first-order difference of the time series, and the auto correlation function (ACF) respectively. The first order difference of the FMCG time series is presented in Figure 7. It is clear that the first-order difference time series is a stationary one, as the mean and the variance of the first-order difference time series are approximately constant. Hence the value of $d=1$ is cross-verified. Now, we plot the partial auto correlation 


\section{Journal of Economics Library}

function (PACF) and the auto correlation function (ACF) to cross-check the values of the parameters $p$ and $q$. Figure 8 depicts the PACF of the FMCG sector time series. It is clear that except for lag $=0$, partial correlation values at all lags are insignificant. Hence the value of $p=0$ is also verified. Figure 9 shows that minimum integral value of lag beyond which all autocorrelation values are insignificant is 1 . Therefore, $q=1$ is also verified. Hence, it now confirmed that the FMCG sector time series for the period January 2010 till December 2015 can be modeled as an ARMA $(0,1,1)$ model. Using the arima() function in $\mathrm{R}$ with its two parameters: (i) the FMCG sector time series R object and (ii) the order $(0,1,1)$ of ARMA, we build the ARIMA model. Finally, we use the function forecast. Arimal ) with two parameters: (i) the ARIMA model and (ii) the time horizon of forecast = 12 months, for forecasting the index values of the time series for all the twelve months of the year 2016. Table 6 presents the results of forecasting using this method, while Figure 10 depicts the actual index values and their corresponding predicted values for all months in the year 2016.

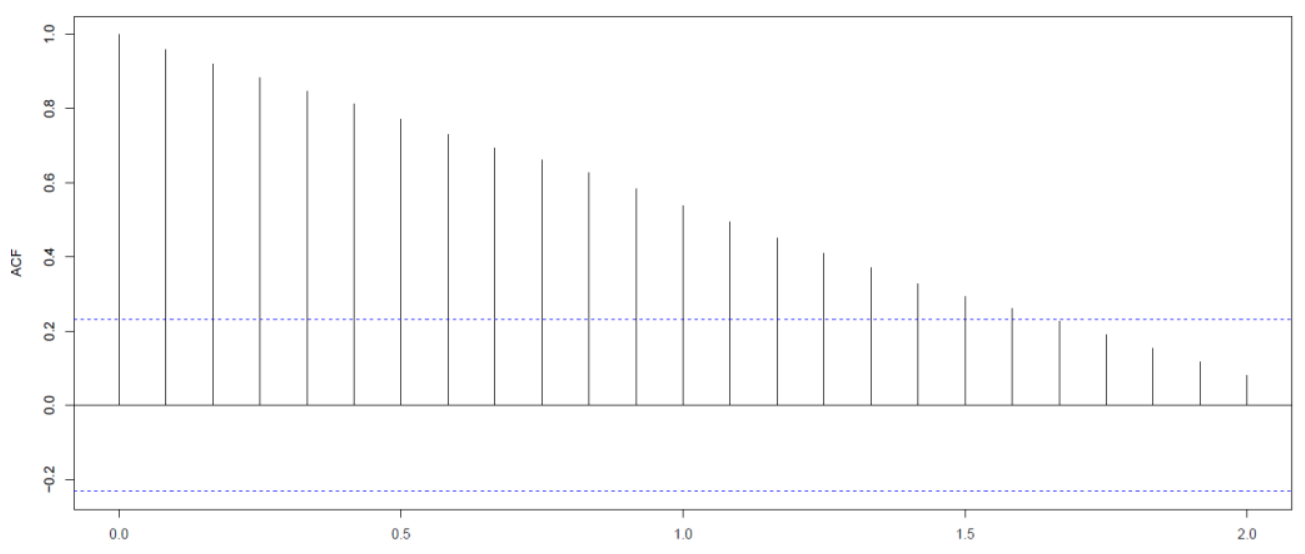

Figure 9. Plot of the auto correlation function (ACF) of the FMCG sector time series with max lag of 2 years (Period: Jan 2016 - Dec 2016)

Table 6. Computation Results using MethodV

\begin{tabular}{ccccc}
\hline Month & Actual Index & Forecasted Index & \% Error & RMSE \\
\hline (A) & $(\mathrm{B})$ & $(\mathrm{C})$ & $(\mathrm{C}-\mathrm{B}) / \mathrm{B} * 100$ & \\
Jan & 7439 & 7875 & 5.86 & \\
Feb & 7114 & 7875 & 10.70 & \\
Mar & 7692 & 7875 & 2.38 & \\
Apr & 7697 & 7875 & 2.31 & \\
May & 8045 & 7875 & 2.11 & 5 \\
Jun & 8453 & 7875 & 6.84 & \\
Jul & 8725 & 7875 & 9.74 & \\
Aug & 8822 & 7875 & 10.73 & \\
Sep & 8461 & 7875 & 6.93 & \\
Oct & 8511 & 7875 & 7.47 & \\
Nov & 8071 & 7875 & 2.43 & \\
Dec & 8131 & 7875 & 3.15 & \\
\hline
\end{tabular}

Observations: It is evident from Table 6 that most of the error percentage values are quite moderate. The lowest value of error percentage had been 2.11 that occurred in the month of May 2016, while the highest value of error percentage was 10.73, observed in the month of August 2016. The RMSE value for this method is found to be 553 which is 6.83 per cent of the mean value of the FMCG sector index during the period January 2016 till December 2016. The mean value of the FMCG sector index has been 8097. Considering the fact that this method uses a long forecast horizon of 12 months, the error percentage values are quite low. This is attributed to the fact that the FMCG sector index experienced a very modest increase during the period January 2016 till December 2016 - the index started with a value of 7439 in January 2016 and attained a value of 8131 in 


\section{Journal of Economics Library}

December 2016. The HoltWinters method with forecast horizon of 12 forecasted a constant average value of 7875 for the series with ARIMA parameters $(0,1,1)$ so that the average error for the entire series is minimized. Figure 10 presents a graphical depiction of the actual index values and their corresponding predicted values using Method V.

Method VI: In this approach, we build an ARIMA model with a forecast horizon of one month. The methodology used for building the ARIMA model, however, is exactly identical to that used in Method V. The difference in Method V and Method VI lies in different values of forecast horizon used in these methods. While Method V uses a forecast horizon of 12 months, we use a forecast horizon of 1 month in Method VI. Since, in Method VI, forecast is made only one month in advance, the training data set used for building the ARIMA model constantly increases in size, and hence, we re-evaluate the parameters of the ARIMA model every time we use it in forecasting. In other words, for each month of 2015, before we make the forecast for the next month, we compute the values of the parameters of the ARIMA model. Computation of the values of ARIMA parameters $p, d$, and $q$ showed that for the period January 2016 till June 2016, the ARIMA model was (0, $1,1)$, while the for the remaining period July 2016 till December 2016, it was $(0,1$, 0 ). Table 7 presents the forecasting results for Method VI. Figure 11 depicts the actual index values of the FMCG sector and their corresponding predicted values for this method of forecasting.

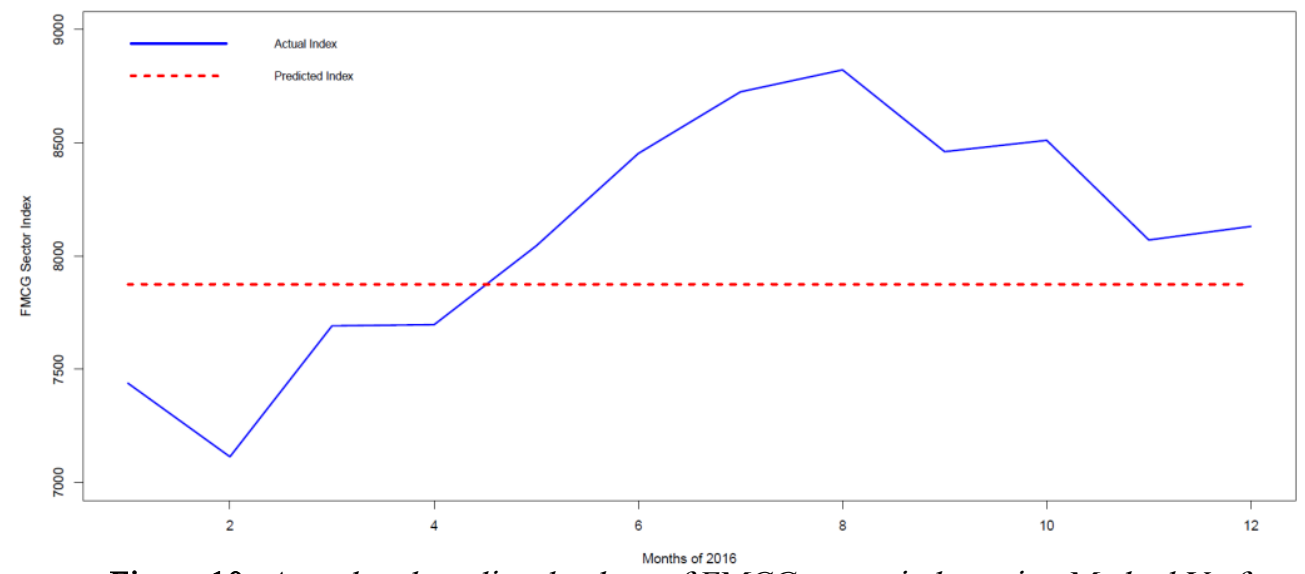

Figure 10. Actual and predicted values of FMCG sector index using Method V of forecasting. (Period: Jan 2016 - Dec 2016).

Table 7. Computation Results using Method VI

\begin{tabular}{ccccc}
\hline Month & Actual Index & Forecasted Index & \% Error & RMSE \\
\hline (A) & $(\mathrm{B})$ & $(\mathrm{C})$ & $(\mathrm{C}-\mathrm{B}) / \mathrm{B} * 100$ & \\
Jan & 7439 & 7875 & 5.86 & \\
Feb & 7114 & 7475 & 5.07 & \\
Mar & 7692 & 7114 & 7.51 & \\
Apr & 7697 & 7640 & 0.74 & \\
May & 8045 & 7692 & 4.39 & \multirow{2}{*}{. } \\
Jun & 8453 & 8016 & 5.17 & \\
Jul & 8725 & 8453 & 3.12 & \\
Aug & 8822 & 8725 & 1.10 & \\
Sep & 8461 & 8822 & 4.27 & \\
Oct & 8511 & 8461 & 0.59 & \\
Nov & 8071 & 8511 & 5.45 & \\
Dec & 8131 & 8071 & 0.74 & \\
\end{tabular}




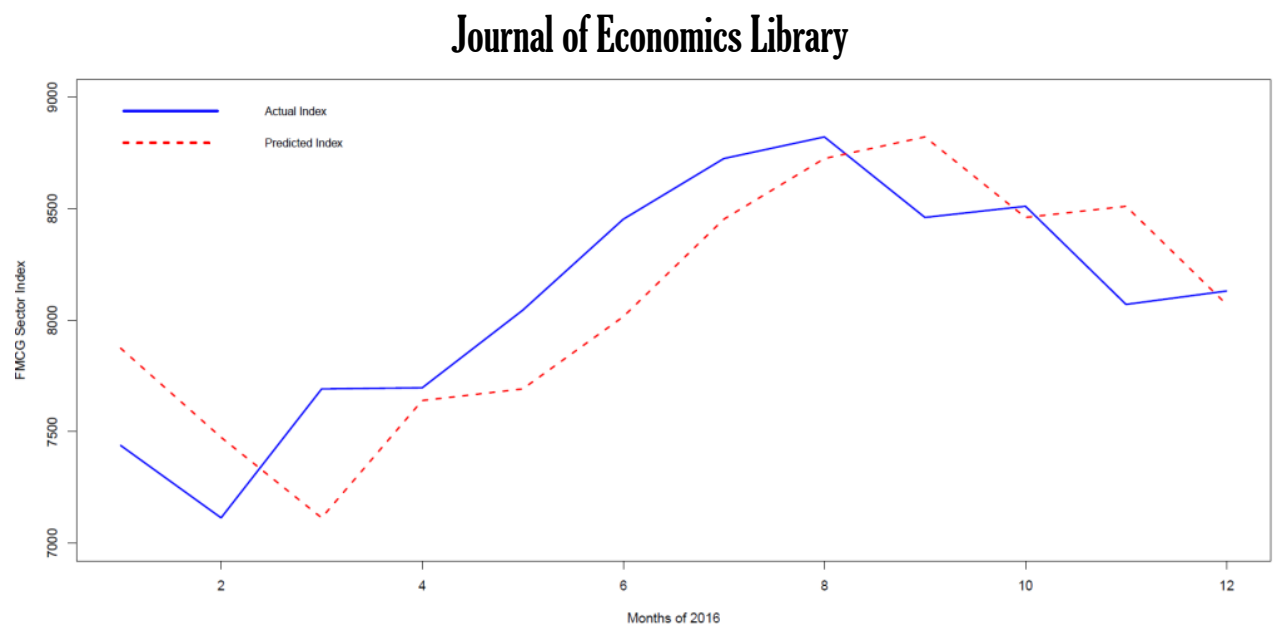

Figure 11. Actual and predicted values of FMCG sector index using Method VI of forecasting. (Period: Jan 2016 - Dec 2016).

Observations:From Table 7, it is evident that the error percentage values for all months of the year 2016 are very low. The lowest value of error percentage was found to be 0.59 in the month of October 2016, while the highest value of error was 7.51 per cent in the month of March 2016. The RMSE value for Method VI of forecasting is found to be 340. The mean value of the index of the FMCG sector for the period January 2016 till December 2016 is 8097 . Hence, the RMSE value is just 4.20 percent of the mean value of the actual index of the FMCG sector. This indicates that Method VI has been highly accurate in forecasting the FMCG sector index values. The high level of accuracy of Method VI may be attributed to its short forecast horizon of one month. The short forecast horizon is able to catch the changing pattern of the time series very effectively. This has resulted into a very small error in forecasting. It is clearly evident from Figure 11 that the forecasted time series values exactly followed the pattern of the time series of the actual index values of the FMCG sector.

\section{Summary of Forecasting Results}

In Table 8, we summarize the performance of the six forecasting methods that we have used. For the purpose of comparison between these methods, we have chosen six metrics: (i) minimum (Min) error rate, (ii) maximum (Max) error rate, (iii) mean error rate, (iv) standard deviation (SD) of error rates, and (v) root mean square error (RMSE), and (vi) the ratio of RMSE to the mean of the actual index values in percentage. For Method I, II, IV and V the mean of the index values are the same, being the mean of the actual index values of the FMCG sector for the twelve months in the year 2016. This mean value is found to be equal to 8097. For Method III and IV, however, the mean of the index values are the mean of the sum of the actual trend and seasonal values during the period July 2015 till June 2016. This mean value of the sum of the trend and seasonal values is found to be equal to 7880. Since the RMSE values for Methods I, II, IV and V and those for Method III and IV are computed against different set of actual values, hence, instead of the raw RMSE value, the percentage of RMSE to the mean value of the index serves as a better metric for comparing different methods of forecasting. Accordingly, we have ranked the forecasting methods

Table 8 presents the comparative analysis of the six forecasting methods. It can be seen that Method III that uses the sum of the forecasted trend values using HoltWinters() function of horizon 12 months and the past seasonal values to predict the sum of the future trends values and the new seasonal values, has performed has produced the lowest percentage value of the ratio of RMSE to the mean index value. In fact, Method III has produced lowest values for all other metrics too. Hence, Method III clearly turns out to be the most accurate among all the six methods. On the other hand, the performance of Method IV has been the 


\section{Journal of Economics Library}

worst since it has produced the highest values for four metrics: ratio of RMSE to the mean value, min errors, max error and mean error. The performance of Methods I, II and VI are comparable since in terms of all the five metrics, these three methods are very close to each other. Method V, however, performed worse than these three methods producing a higher value of 6.83 per cent for the ratio of the RMSE to the mean index value.

Table 8. Comparison of the Performance of the Forecasting Methods

\begin{tabular}{lcccccc}
\hline $\begin{array}{c}\text { Metrics } \\
\text { Methods }\end{array}$ & $\begin{array}{c}\text { Min } \\
\text { Error }\end{array}$ & $\begin{array}{c}\text { Max } \\
\text { Error }\end{array}$ & $\begin{array}{c}\text { Mean } \\
\text { Error }\end{array}$ & $\begin{array}{c}\text { SD of } \\
\text { Errors }\end{array}$ & RMSE & $\begin{array}{c}\text { RMSE / Mean Index } \\
\text { Value Percentage }\end{array}$ \\
\hline Method 1 & 0.09 & 8.62 & 3.86 & 2.84 & 373 & 4.61 \\
Method II & 0.34 & 6.57 & 3.66 & 2.34 & 343 & 4.24 \\
Method III & 0.02 & 2.64 & 1.39 & 0.99 & 132 & 1.67 \\
Method IV & 4.86 & 14.38 & 11.42 & 2.91 & 927 & 11.74 \\
Method V & 2.11 & 10.73 & 5.89 & 3.37 & 553 & 6.83 \\
Method VI & 0.59 & 7.51 & 3.67 & 2.36 & 340 & 4.20 \\
\hline
\end{tabular}

\section{Related Work}

Several approaches and techniques are proposed by researchers in the literature for forecasting of daily stock prices. Among these approaches, neural networkbased approaches are extremely popular. Mostafa (2010) proposed a neural network-based technique for predicting movement of stock prices in Kuwait. Kimoto et al. (1990) presented a technique using neural network based on historical accounting data and various macroeconomic parameters to forecast variations in stock returns. Leigh et al. (2005) demonstrated methods of predicting stock prices and stock market index movements in the New York Stock Exchange (NYSE) during the period 1981 - 1999 using linear regression and simple neural network models. Hammad et al. (2009) illustrated how the output of an artificial neural network (ANN) model can be made to converge and produce highly accurate forecasting of stock prices. Dutta et al. (2006) used ANN models for forecasting closing index values the BSE during the period January 2002 till December 2003. Ying et al. (2009) used Bayesian Network (BN) - based approach to forecast stock prices of 28 companies listed in DJIA (Dow Jones Industrial Average) during 1988-1998. Tsai \& Wang (2009) illustrated how and why the forecasting accuracy of BN-based approaches usually is higher than that obtained using traditional regression and neural network-based methods. Tseng et al. (2012) demonstrated the application of traditional time series decomposition, HoltWintersmodels, Box-Jenkins method and artificial neural networks in forecasting prices of randomly selected 50 stocks during the period September 1998 till December 2010. The study found that forecasting errors values are low for Box-Jenkins method, HoltWinters model and normalized neural network model, while higher values of error were observed in time series decomposition method and non-normalized neural network model. Moshiri \& Cameron (2010) built a back propagation network (BPN) with econometric models for forecasting the level of inflation using the techniques: (i) Box-Jenkins Autoregressive Integrated Moving Average (BJARIMA) model, (ii) Vector Autoregressive (VAR) model and (ii) Bayesian Vector Autoregressive (BVAR) model. Thenmozhi (2001) applied chaos theory for examining the pattern of changes of stock prices in Bombay Stock Exchange (BSE) during the period August 1980 till September 1997, and found that the daily and weekly returns of BSE index exhibited nonlinear trends, while the movement pattern of the time series of BSE index was found to be weakly chaotic. Hutchinson et al. (1994) proposed a novel approach using the principles of learning networks for estimating the price of a derivative.

Predictive models based on ANN are found to be extremely accurate in forecasting stock prices. Shen et al. (2007), Jaruszewicz \& Mandziuk (2004), Ning et al. (2009), Pan et al. (2005), Hamid \& Iqbal (2004), Chen et al. (2005), Chen et al. (2003), Hanias et al. (2007) and de Faria et al. (2009) demonstrated the effectiveness of ANN-based models in their forecasting ability of stock price 


\section{Journal of Economics Library}

movements. Many applications of hybrid systems in stock market time series data analysis have also been proposed in the literature. Wu et al. (2008), Wang \& Nie (2008), Perez-Rodriguez et al. (2005), Leung et al. (2000) and Kim (2004) proposed applications of hybrid systems in stock price prediction.

In the literature, researchers have also proposed several forecasting techniques which have particularly focused on various issues in the FMCG domain. Lewandowska (2012) presented a work that analyzed a very high level of the shrinkage in the FMCG sector in the European and global markets. The author observed that in order to reduce losses and their impact on the profits of the companies, it is necessary to grant liability for their reduction to the members of the board of directors. Rakicevic \& Vujosevic (2015) presented a real-world sales forecasting problem in a FMCG supply chain. The authors used several sales forecasting methods such as: estimation of the last period, average of all observations, moving average, weighted moving average, exponential smoothing, Holt's model of forecasting and Winter's forecasting model. The authors compared these forecasting methods with respect to three metrics: RMSE, mean absolute percentage error (MAPE) and tracking signal (TS). Vayvay et al. (2013) modeled a supply chain for FMCG products and proposed its working styles, tools, organization structure, relations with other departments, procedures and all the processes in management of supply chain. While forecasting the demand of FMCG products, the authors also took into account return of stale or damaged products that are returned from the customer to the company. Several forecasting techniques for supply chain management are also proposed. Vriens \& Versteijnen (2007) discussed dynamics of food industry that makes forecasting and planning so critical. The authors also presented various key issues in business planning process such as: planning of promotion for enhanced sales, collaboration in the upstream supply chain, criticality of the roles of marketing and sales department in demand forecasting of FMCG products, analysis and resolution of capacity bottleneck the supply chain, forecasting of the effectiveness of introduction of new FMCG products etc. Based on these issues, the authors proposed guidelines for implementation of responsive forecasting and planning process in the food industry. Doganis et al. (2006) presented a complete framework for developing nonlinear time series sales forecasting model for food products. The framework proposed by the authors is a combination of two artificial intelligence technologies: (i) radial basis function (RBF) neural network architecture and (ii) a specially designed genetic algorithm (GA). Singhi et al. (2015) in their report of the Confederation of Indian Industries (CII) and the Boston Consulting Group (BCG) identified the key trends reshaping the demand, and assessed the impact of these trends on the shape of consumption over the next decade. The authors have also laid down the imperatives for companies going forward to win in the new world of competition. The authors incorporated inputs from leading CEOs on the key trends impacting the FMCG industry, and leveraged proprietary data and research conducted by BCG. Kunc (2005) presented a detailed case study to illustrate competitive dynamics of FMCG industry using a behavioral model.

In contrast to the work mentioned above, our approach in this paper is based on structural decomposition of time series of the FMCG sector index in India during the period January 2010 till December 2016. Based on the decomposition of the time series, we identified several interesting characteristics of the FMCG sector India. We particularly investigated the nature of the trend, seasonality pattern and degree of randomness of the time series. After analyzing the nature of the FMCG time series, we proposed six forecasting techniques for predicting the index values of the sector for each month of the year 2016. We computed the accuracies of each of the forecasting techniques, and critically analyzed under what situations a particular technique performs better than the other techniques. Since the forecasting methods proposed in this paper are all generic in nature, these methods can be very effectively applied in forecasting the future trends and behavior of time 


\section{Journal of Economics Library}

series index values of other sectors of economy of India or other countries in the world.

\section{Conclusion}

This paper has presented a time series decomposition-based approach for analyzing the behavior of the time series of the FMCG sector of the Indian economy during the period January 2010 till December 2016. Algorithms and library-defined functions in the $\mathrm{R}$ programming language have been used to decompose the time series index values into three components- trend, seasonal, and random. The decomposition results of the time series provided with several important insights into the behavior exhibited by the FMCG sector time series during the period under our study. Based on the decomposition results, the degree of seasonality and randomness in the time series have been computed. Particularly, it has been possible to identify the months during which the seasonal component in the FMCG time series plays a major role. It is observed that while the month of September experiences the highest seasonality in the FMCG sector, for the month of February the seasonal effect is the lowest. The random component in the time series has been found to be very moderate with the mean value of the percentage of random component to the aggregate time series value being only 2.4. Although, the trend is the most dominant component in the time series, the value of trend increased at a sluggish rate over the period of seven year during January 2010 till December 2016. After a careful analysis of the decomposition results of the FMCG sector index time series, we have proposed six methods for forecasting the time series index values. The six method of forecasting involved different algorithms of forecasting and different lengths of forecast horizon. It has been observed that Method III that uses the sum of the forecasted trend values using HoltWinters() function of horizon 12 months and the past seasonal values to predict the sum of the future trends values and the new seasonal values has performed best yielding the lowest percentage value of the ratio of RMSE to the mean index value. However, Method IV that predicts the trend values using a linear regression model is found to produce the highest value of the ratio of the RMSE to the mean index value, thereby exhibiting the worst performance among the six methods of forecasting. The performance of HoltWinters method with forecast horizon of 12 months and 1 month and ARIMA method with forecast horizon of 1 month have been quite satisfactory with the RMSE to mean index ratio for these method not exceeding 4.7. However, ARIMA with a forecast horizon of 12 months yielded a higher value of 6.83 percent for the RMSE to mean index value.

While the results in this work provide enough valuable insights into the characteristics of the FMCG index time series in India, and they also serve as guidelines for choosing an appropriate forecasting framework for predicting the future index values of the time series, these results can be extremely useful for constructing an optimized portfolio of stocks. Performing similar exercise on different sectors will enable analysts to understand the individual characteristics of the trend, seasonality and randomness of those sectors. This information can be suitably leveraged by portfolio managers in identifying the timing of buy and sell of stocks from different sectors thereby designing an efficient and optimized portfolio. 


\section{Journal of Economics Library}

\section{References}

Chen, A.-S., Leung, M.T. \& Daouk, H. (2003). Application of neural networks to an emerging financial market: forecasting and trading the Taiwan stock index. Operations Research in Emerging Economics, 30(6), 901- 923. doi. 10.1016/S0305-0548(02)00037-0

Chen, Y., Dong, X. \& Zhao, Y. (2005). Stock index modeling using EDA based local linear wavelet neural network. Proceedings of International Conference on Neural Networks and Brain, Beijing, China, pp. 1646-1650. doi. 10.1109/ICNNB.2005.1614946

Coghlan, A. (2015). A Little Book of R for Time Series, Release 02. Accessed on: May 10, 2017 [Retrieved from].

de Faria, E.L., Albuquerque, M.P., Gonzalez, J.L., Cavalcante, J.T.P., \& Albuquerque, M.P. (2009) Predicting the Brazilian stock market through neural networks and adaptive exponential smoothing methods. Expert Systems with Applications, 36(10), 12506-12509. doi. 10.1016/j.eswa.2009.04.032

Doganis, P., Alexandridis, A., Patrinos, P., \& Sarimveis, H. (2006). Time series sales forecasting for short shelf-life food products based on artificial neural networks and evolutionary computing Journal of Food Engineering, 75(2), 196-204. doi. 10.1016/j.jfoodeng.2005.03.056

Dutta, G. Jha, P., Laha, A., \& Mohan, N. (2006). Artificial neural network models for forecasting stock price index in the Bombay Stock Exchange. Journal of Emerging Market Finance, 5(3), 283-295. doi. 10.1177/097265270600500305

Hamid, S.A., Iqbal, Z. (2004). Using neural networks for forecasting volatility of S\&P 500 index futures prices. Journal of Business Research, 57(10), 1116-1125. doi. 10.1016/S01482963(03)00043-2

Hammad, A.A.A., Ali, S.M.A., \& Hall, E.L. (2007). Forecasting the Jordanian stock price using artificial neural network. Intelligent Engineering Systems through Artificial Neural Networks, Vol 17, Digital Collection of The American Society of Mechanical Engineers. doi. 10.1115/1.802655.paper42

Hanias, M., Curtis, P. \& Thalassinos, J. (2007). Prediction with neural networks: the Athens stock exchange price indicator. European Journal of Economics, Finance and Administrative Sciences, 9, 21-27.

Hutchinson, J.M., Lo, A.W., \& Poggio, T. (1994). A nonparametric approach to pricing and hedging derivative securities via learning networks. Journal of Finance, 49(3), 851-889. doi $10.3386 / \mathrm{w} 4718$

Ihaka, R., \& Gentleman, R. (1996). A language for data analysis and graphics. Journal of Computational and Graphical Statistics, 5(3), 299-314. doi. 10.2307/1390807

Jaruszewicz, M., \& Mandziuk, J. (2004). One day prediction of NIKKEI index considering information from other stock markets. Proceedings of the International Conference on Artificial Intelligence and Soft Computing, 3070, 1130-1135. doi. 10.1007/978-3-540-24844-6 177

Kim, K.-J. (2004). Artificial neural networks with feature transformation based on domain knowledge for the prediction of stock index futures. Intelligent Systems in Accounting, Finance \& Management, 12(3), 167-176. doi. 10.1002/isaf.252

Kimoto, T., Asakawa, K., Yoda, M. \& Takeoka, M. (1990). Stock market prediction system with modular neural networks. Proceedings of the IEEE International Conference on Neural Networks, San Diego, pp. 1-16, CA, USA. doi. 10.1109/IJCNN.1990.137535

Kunc, M. (2005). Illustrating the competitive dynamics of an industry: the fast-moving consumer goods industry case study. Proceedings of the $23^{\text {rd }}$ International Conference of the System Dynamics Society, pp. 1-42, Boston, MA, USA, July, 2005.

Leigh, W., Hightower, R., \& Modani, N. (2005). Forecasting the New York Stock Exchange composite index with past price and interest rate on condition of volume spike. Expert Systems with Applications, 28(1), 1-8. doi. 10.1016/j.eswa.2004.08.001

Leung, M.T., Daouk, H., \& Chen, A.-S. (2000). Forecasting stock indices: a comparison of classification and level estimation models. International Journal of Forecasting, 16(2), 173-190. doi. 10.1016/S0169-2070(99)00048-5

Lewandowska, J. (2012). Identification losses in the FMCG1 sector in the light of the European and global researchers. Proceedings of FIKUSZ'12 Symposium for Young Researchers, pp. 101-110, Budapest, Hungary, November 2012.

Moshiri, S., \& Cameron, N. (2010). Neural network versus econometric models in forecasting inflation. Journal of Forecasting, 19(3), 201-217. doi. 10.1002/(SICI)1099131X(200004)19:3<201::AID-FOR753>3.0.CO;2-4

Mostafa, M. (2010). Forecasting stock exchange movements using neural networks: empirical evidence from Kuwait. Expert Systems with Application, 37(9), 6302-6309. doi. 10.1016/j.eswa.2010.02.091

Ning, B., Wu, J., Peng, H., \& Zhao, J. (2009). Using chaotic neural network to forecast stock index Advances in Neural Networks, Lecture Notes in Computer Science, Vol.5551, pp. 870-876 Springer-Verlag, Heidelberg, Germany. doi. 10.1007/978-3-642-01507-6 98

Pan, H., Tilakaratne, C., \& Yearwood, J. (2005). Predicting the Australian stock market index using neural networks exploiting dynamical swings and intermarket influences. Journal of Research and Practice in Information Technology, 37(1), 43-55. doi. 10.1007/978-3-540-89378-3 53 


\section{Journal of Economics Library}

Perez-Rodriguez, J.V., Torra, S., \& Andrada-Felix, J. (2005). Star and ANN models: forecasting performance on the Spanish IBEX-35 stock index. Journal of Empirical Finance, 12(3), 490-509. doi. 10.1016/j.jempfin.2004.03.001

Rakicevic, Z., \& Vujosevic, M. (2015). Focus forecasting in supply chain: the case study of fast moving consumer goods company in Serbia. Serbian Journal of Management, 10(1), 3-17. doi. $10.5937 / \mathrm{sjm} 10-7075$

Sen J., \& Datta Chaudhuri, T. (2016a). Decomposition of time series data of stock markets and its implications for prediction - an application for the Indian auto sector. Proceedings of the $2^{\text {nd }}$ National Conference on Advances in Business Research and Management Practices (ABRMP'16), pp. 15-28, Kolkata, India, January, 2016. doi. 10.13140/RG.2.1.3232.0241

Sen, J., \& Datta Chaudhuri, T. (2016b). A framework for predictive analysis of stock market indices a study of the Indian auto sector. Calcutta Business School (CBS) Journal of Management Practices, 2(2), 1-20. doi. 10.13140/RG.2.1.2178.3448

Sen, J., \& Datta Chaudhuri, T. (2016c). An alternative framework for time series decomposition and forecasting and its relevance for portfolio choice: a comparative study of the Indian consumer durable and small cap sectors. Journal of Economic Library, 3(2), 303-326. doi. 10.1453/jel.v3i2.787

Sen, J., \& Datta Chaudhuri, T. (2016d). An investigation of the structural characteristics of the Indian IT sector and the capital goods sector - an application of the R programming in time series decomposition and forecasting. Journal of Insurance and Financial Management, 1(4), 68-132.

Sen, J., \& Datta Chaudhuri T. (2016e). Decomposition of time series data to check consistency between fund style and actual fund composition of mutual funds. Proceedings of the 4 International Conference on Business Analytics and Intelligence (ICBAI 2016), Bangalore, India, December 19-21. doi. 10.13140/RG.2.2.14152.93443

Shen, J., Fan, H. \& Chang, S. (2007). Stock index prediction based on adaptive training and pruning algorithm. Advances in Neural Networks, Lecture Notes in Computer Science, Vol 4492, pp. 457-464, Springer-Verlag, Heidelberg, Germany. doi. 10.1007/978-3-540-72393-6 55

Singhi, A., Jain, N. \& Puri, N. (2015). Re-Imagining FMCG in India. CII National Summit Report, December 2015, pp, 1-68. Accessed on: May 10, 2017. [Retrieved from].

Thenmozhi, M. (2006). Forecasting stock index numbers using neural networks. Delhi Business Review, 7(2), 59-69. Accessed on: May 10, 2017. [Retrieved from].

Tsai, C.-F. \& Wang, S.-P. (2009). Stock price forecasting by hybrid machine learning techniques. Proceedings of International Multi Conference of Engineers and Computer Scientists, pp. 755765, Hong Kong, March 2009.

Tseng, K-C., Kwon, O., \& Tjung, L.C. (2012). Time series and neural network forecast of daily stock prices. Investment Management and Financial Innovations, 9(1), 32-54.

Vayvay, O., Dogan, O., \& Ozel, S. (2013). Forecasting techniques in fast moving consumer goods supply chain: a model proposal. International Journal of Information Technology and Business Management, 16(1), 118 - 128.

Vriens, A., \& Versteijnen, E. (2007). Forecasting \& Planning in the Food Industry. EyeOn White Paper. Accessed on: May 10, 2017. [Retrieved from].

Wang, W., \& Nie, S. (2008). The performance of several combining forecasts for stock index. International Seminar on Future Information Technology and Management Engineering, pp. 450455, Leicestershire, United Kingdom, November 2008. doi. 10.1109/FITME.2008.42

Wu, Q., Chen, Y., \& Liu, Z. (2008). Ensemble model of intelligent paradigms for stock market forecasting. Proceedings of the $I^{\text {st }}$ International Workshop on Knowledge Discovery and Data Mining, pp. 205 - 208, Washington, DC, USA, January 2008. doi. 10.1109/WKDD.2008.54

Zhu, X., Wang, H., Xu, L., \& Li, H. (2008). Predicting stock index increments by neural networks: the role of trading volume under different horizons. Expert Systems with Applications, 34(4), 3043-3054. doi. 10.1016/j.eswa.2007.06.023

\section{Copyrights}

Copyright for this article is retained by the author(s), with first publication rights granted to the journal. This is an open-access article distributed under the terms and conditions of the Creative Commons Attribution license (http://creativecommons.org/licenses/by-nc/4.0).

JEL, 4(2), J. Sen, \& T.D. Chaudhuri, p.206-226. 